\title{
Perspectives of Brothel Leaders and HIV Prevention Experts on the Role of Gatekeepers on Improving Condom Use by Female Sex Workers in Abuja, Nigeria
}

\author{
Uchenna O. Okafor ${ }^{1}$, Rik Crutzen ${ }^{1}$, Egbe A. Awo ${ }^{2} \&$ Bart Van den Borne ${ }^{1}$ \\ ${ }^{1}$ Department of Health Promotion, Maastricht University, Netherlands \\ ${ }^{2}$ Society for Family Health, Nigeria \\ Correspondence: Uchenna Okafor Health promotion Department, Maastricht University, Netherlands. Tel: \\ 234-802-641-4281. E-mail: utch_19@yahoo.co.uk
}

Received: July 30, 2017 Accepted: September 12, 2017 Online Published: September 18, 2017

doi:10.5539/gjhs.v9n10p183

URL: https://doi.org/10.5539/gjhs.v9n10p183

\begin{abstract}
A qualitative study using in-depth interviews explored the perceptions and views of brothel leaders and HIV program experts on the acceptability and adoptability of using gatekeepers in interventions aimed at improving Female Sex Workers' (FSWs) condom use in Nigeria. Brothel leaders are an influential group within the FSWs' social and physical environment and their attitudes, beliefs and actions can influence the immediate brothel environment and the adoption of interventions within the brothel. HIV prevention experts make key decisions on the content and strategies adopted for HIV prevention efforts and also influence the design and implementation of HIV prevention strategies within programs. Four themes illustrating the benefits and barriers of the inclusion of gatekeepers within the immediate environment of the FSW were identified. Results show that brothel leadership inclusion in HIV prevention efforts could exert potential positive influence on the immediate brothel environment. Brothel leaders can support the institution of establishment policies supporting consistent condom use by the FSWs, promotion of HIV awareness, resolution of conflicts and harassments, support to new entrants into sex work and the reinforcement of protective behaviors among the FSWs. The decriminalization of sex work and the inclusion of gatekeepers support into country HIV program guidelines may contribute to mitigating prevalent sociocultural factors limiting FSWs' rights as well as their access to health services. The present study provides insights into the potential positive roles of brothel leaders in improving condom use and other HIV/AIDs related interventions for brothel based FSWs in Abuja, Nigeria from the perspective of brothel leaders and HIV prevention experts.
\end{abstract}

Keywords: Condom use, Female Sex Worker, HIV, Interventions, Brothel leaders

\section{Introduction}

Surveillance data by the Federal Ministry of Health in Nigeria show that Female Sex Workers (FSWs) have a high HIV prevalence and record the second highest prevalence of HIV compared to other sub-populations in the country with a HIV prevalence rate of 19.4\%. (FMOH, 2014) An influential group of people within the FSWs' social and physical environment, who serve as gatekeepers, are those managing the FSWs (e.g., managers, chairladies, owners of establishments/brothels). They have a reciprocal financial relationship with FSWs and rely on FSWs to make money. Alternatively, FSWs are dependent on these gatekeepers for the use of their establishment for financial gain (Yang et al., 2005). Gatekeepers exert power and control over FSWs and the lack of gatekeeper support as well as abusive FSW-gatekeeper relationships can be barriers to preventive behaviours. An emphasis on making more money at the expense of safety, for example, may contribute to inconsistent condom use by the FSWs (Okafor, Crutzen, Okekearu, Adebajo, \& Van den Borne, 2017; Xia \& Yang, 2005). Sex work is criminalized and highly stigmatized in Nigeria resulting in FSWs operating clandestinely. Despite this, sex work continues to thrive in various forms with the brothel system as a one of the main types of sex work settings prevalent in the country. The vulnerability of FSWs and the increased risks faced as a result of the interplay between their sex, work settings and social factors influencing sex work in the country has been brought to the fore by the HIV epidemic. Sociocultural factors prevalent in the country, including laws, policies and societal norms, continue to limit the civil, social and economic rights of FSWs such as their access to health care, employment conditions, type of sex 
venue, trust in a stable partner, gender inequities, stigma and discrimination.

HIV prevention programs in Asia and the Dominican Republic have demonstrated how interactions between gatekeepers and FSWs can be used in a positive way and how such interactions can be incorporated to improve condom use practices (Hong, Fang, Li, Liu, \& Li, 2008; Li, Li, Stanton, Fang, \& Zhao, 2010; D. Morisky, Stein, Chiao, Ksobiech, \& Malow, 2006; Xia \& Yang, 2005; Zang, Li, \& Y., 2014). Gatekeepers have also been shown in various studies to play significant roles in HIV risk reduction for FSWs including facilitating consistent condom use (Hong et al., 2008; Yang et al., 2005; Zang et al., 2014). HIV prevention programs that take into account the unique roles of gatekeepers are crucial to enhance FSW health and HIV prevention efforts as a whole. In Nigeria and West Africa, limited research exists on the role of gatekeepers play in facilitating consistent condom use by FSWs. It is important therefore for research to provide more insights into this in order to inform future programming and strategies in the region.

A pilot behavioural intervention aimed at measuring the feasibility and suitability of using brothel leaders to improve condom use by Brothel-Based (BB) FSWs was designed (Okafor, Crutzen, Adebajo, Okekearu, \& Van den Borne, 2017) and implemented. The attitudes, beliefs and practices of the brothel leaders can influence the immediate brothel environment of the FSW and the adoption of interventions within the brothel (Urada, Morisky, Hernandez, \& Strathdee, 2013). Program experts are significant stakeholders in HIV prevention efforts for FSWs and determine the contents of HIV prevention programs while brothel leaders who have powerful relationships with the FSWs can make decisions on the use and adoption of the programs by the FSWs (Page, 2002). Hence, brothel leaders can influence the successful adoption of HIV prevention interventions. The diffusion of innovations theory by Rogers (Rogers, 2003; Rogers \& Kincaid, 1981) indicates that the adoption of an innovation is influenced by the quality of the innovation, the qualities inherent in the targeted individuals to adopt and use the innovation and the innovation's compatibility with the potential adopter or organization's norms and procedures. So, the design of a behavioural intervention to address inconsistent condom use by FSWs should be consultative and take into consideration the complexities within the immediate social environment the FSW interacts with in addition to the individual factors (Jana, Basu, Rotheram-Borus, \& Newman, 2004).

This study explores the perceptions and views of brothel leaders and HIV program experts on the acceptability and adoptability of using gatekeepers in interventions aimed at improving FSW condom use in Nigeria. Perceptions of the suitability of this approach for these gatekeepers as well as views on possible improvements for HIV prevention interventions were also explored. This is necessary to gain more insights into the potential benefits of including this very influential group within the FSWs' immediate environment and their impact on the adoption of preventive behaviours by the FSWs.

\section{Methodology}

A qualitative study using in-depth interviews was conducted to explore perceptions and views of brothel leaders and HIV prevention experts. Eighteen in-depth interviews were conducted in Abuja, Nigeria with thirteen brothel leaders (chairladies, managers and/or brothel owners) and five HIV prevention experts. The interviews focused on how brothel leaders and HIV prevention experts perceive the roles of gatekeepers in the promotion of consistent condom use by FSWs. Ten brothel managers, owners and chairladies of brothels within the Federal Capital Territory (FCT) who had been part of a previous pilot condom promotion intervention were invited and eight of them gave consent for the interview. Five additional brothel leaders, who did not participate in the pilot study, were selected from the location of focus and were participating in a peer-led HIV prevention program implemented by the Society for Family Health (SFH) an indigenous non-governmental organization. In addition to this, five HIV prevention experts overseeing large-scale prevention efforts for FSWs in the country were also invited and interviewed.

\subsection{Interviews}

A semi-structured interview guide was prepared based on the diffusion of innovation (Rogers, 2003) and the stakeholder theories (Page, 2002) and the interviews were conducted between January and May 2017. The interview guide (Supplementary file) covered the following: 1) Knowledge of HIV transmission, prevention and management; 2) Benefits and barriers to brothel leadership inclusion; 3) Sexual practices of FSWs; 4) Program improvement

\subsection{Data Collection and Analysis}

Interviews were recorded and transcribed verbatim and each interview transcript was reviewed for accuracy and correct representation of the responses of the participants. The data was analyzed using Nvivo for MAC 11.3, which is a computer assisted qualitative data analysis tool to aid analysis and reporting. Each transcript was read 
and coded for prominent themes and ideas. This was then refined as appropriate as the data was further analyzed. Another independent researcher coded a random selection of data to look for new concepts and to establish consistency of coding. The independent researcher compared the emerging themes with the coding by the authors for new meanings and no new themes were identified.

\subsection{Ethical Approval}

The Institutional Review Board (IRB) of the Institute of Human Virology Nigeria approved the study; Protocol Number: NHREC/10/15/ 2014a-026. Verbal consent was obtained from all participants before the interviews commenced.

\section{Results}

Characteristics of the interviewees are presented in Table 1. Six males and twelve females were interviewed. The perceptions of the participants in this study are presented under four broad themes; benefits of brothel leadership inclusion, barriers to brothel leadership inclusion, barriers to condom use, program and policy considerations.

Table 1. Overview of Interviewed Brothel Leaders and Program Experts

\begin{tabular}{|c|c|c|c|c|}
\hline No & Gender & Status & Job status & Intervention Participation \\
\hline 1 & Female & Brothel Leader & Chair lady & Yes \\
\hline 2 & Male & Brothel Leader & Owner & Yes \\
\hline 3 & Female & Brothel Leader & Owner & No \\
\hline 4 & Female & Brothel Leader & Owner & No \\
\hline 5 & Female & Brothel Leader & Owner & Yes \\
\hline 6 & Male & Brothel Leader & Owner & No \\
\hline 7 & Male & Brothel Leader & Owner & No \\
\hline 8 & Female & Brothel Leader & Chair lady & Yes \\
\hline 9 & Female & Brothel Leader & Chair lady & Yes \\
\hline 10 & Female & Brothel Leader & Chair lady & Yes \\
\hline 11 & Female & Brothel Leader & Owner/Manager & Yes \\
\hline 12 & Female & Brothel Leader & Owner/Manager & No \\
\hline 13 & Female & Brothel Leader & Owner/Manager & Yes \\
\hline 14 & Female & HIV Prevention Expert & Government worker & N/A \\
\hline 15 & Female & HIV Prevention Expert & Government worker & $\mathrm{N} / \mathrm{A}$ \\
\hline 16 & Male & HIV Prevention Expert & Program manager & $\mathrm{N} / \mathrm{A}$ \\
\hline 17 & Male & HIV Prevention Expert & Program manager & $\mathrm{N} / \mathrm{A}$ \\
\hline 18 & Male & HIV Prevention Expert & Program manager & N/A \\
\hline
\end{tabular}

\subsection{Benefits of Brothel Leadership Inclusion}

\subsubsection{Conflict Management}

A possible fall out of the enforcement of condom use within the brothel is conflict and violence from the clients and regular partners of the FSWs. The brothel leaders within the study explained their strategic role in curbing this within the brothel when it arises. A male brothel owner gives his account of how his influence managed such a situation in his brothel:

"Recently, some man came into the brothel and insists with the FSW that he will not use a condom. The girl brings the case to me and I had to talk to the man on the benefits to his health and that of the FSW if he uses condoms" (Chairlady)

Another female brothel leader explains a scenario where she had to mediate between the FSW and a client and prevented violence: 
"A complaint was brought to me by a client who reported that he negotiated sex without condom with one of the girls in the brothel for a much higher price. The girl collected the money and insists that she will not allow him get what he paid for because she did not want to contact HIV. I had to resolve the issue and ask the girl to give back the money."(Chairlady)

Managing harassment from law enforcement is another role for brothel leaders mentioned by both experts and the participating brothel leaders. Law enforcement agents for different reasons often raid sex work establishments. HIV prevention experts mention the role brothel leaders can play in the reduction of harassment of FSWs by law enforcement and their perceptions on the criminalization of sex work in the country:

"Brothel owners are critical in the process of reaching out to law enforcement agents to reduce the harassment of FSWs" (Male HIV prevention expert)

"Even HIV program managers and service providers are skeptical because the law is not very clear in terms of the criminalization of sex work. Some argue that it is criminalized because the law states that solicitation is a crime. Yet it is unclear who is soliciting who, the FSW or the client? So a lot of education and clarification is needed for us to create an enabling environment where we can propose organized-supported care and prevention interventions for FSWs. " (Male HIV prevention expert)

\subsubsection{Support to New Entrants and Young FSWs}

The immaturity and naivety of new entrants into sex work is a key concern in HIV prevention efforts. Brothel leaders believe they have a strategic role within the brothel to educate new entrants appropriately and improve their self-efficacy. A chair lady gives her account of how she educates new FSWs within her brothel:

"When new girls come from the village who have never done this before and don t even know how to speak English, I show them how to use condom and even demonstrate it with her first client. I also teach her how to get over her shame and insist on condom use. I advice her that she should not drink much so that none of her clients can take advantage of her without using condoms." (Chairlady)

Experts explained their views on new entrants and how they contribute to the HIV burden in the country. A female expert with the national HIV/AIDs response explains the outcome of the epidemic appraisals conducted in the country regarding new entrants to sex work:

"The number of newly enrolled or initiated FSWs was made up of the young girls who didn't know anything about HIV prevention. Looking at this age group from the studies we have conducted shows that they bear a higher burden of the epidemic and this emphasizes the need to target them specifically during programming." (Female HIV prevention expert)

\subsubsection{Establishment of a Conducive Environment for HIV Awareness and Protective Behaviours}

Brothel leaders affirmed the added value their inclusion could bring to HIV prevention interventions particularly towards improving condom use by the FSWs within the brothels. Brothel owners who were part of the pilot intervention agreed that an important role they could play towards providing a conducive environment within the brothels was the adoption of the "No condom- no sex" approach within their brothels. They believe this can be enforced in different ways within the establishments by its leadership and supports collectivization of FSWs towards consistent condom use.

"During the evenings, my assistant and I go around to see the condoms used by the girls'. We try to identify girls who seem to have a lot of customers coming to them and go and check them for condom use with the clients." (Chairlady)

HIV prevention experts explain that in most brothels, the brothel managers or owners are the custodians of the commodities and can sell them at a very subsidized rate and ensure that appropriate conditions for adherence to the "no condom no sex rule" within the brothel exists. Prevention experts explain their views on how brothel leaders can positively influence consistent condom use and foster linkages to health services for the FSWs within the brothel:

"Having the no condom no sex rule among them is important and needs to be enforced. The brothel owners, managers and chairladies need to know about it and lead in enforcing it." (Female HIV prevention expert)

"Brothel leaders could also help in facilitating linkages to other health interventions for FSWs i.e. STI management, antiretroviral therapy and HIV testing services. "(Male HIV Prevention Expert)

Both brothel leaders and experts acknowledge that the reputation of the brothel benefits immensely from the implementation of the HIV prevention interventions and state that efforts should be made to educate the brothel 
leaders on this towards enhancing their understanding of the health benefits to the FSWs and getting their consent and buy-in for the implementation of the program.

"For the 'No condom, No sex'strategy to take hold within the brothel, you need the approval of the brothel owners but again you also need to paint a picture of the benefits to the brothel owners because they are business minded." (Male HIV prevention expert)

\subsubsection{HIV/AIDs Awareness Creation and Prevention Efforts}

Many participants who were brothel leaders explained the activities adopted by them towards improving the risk perception of the FSWs within their establishment. Many participants, both those who had been part of the pilot intervention and those who had not, reported that they had personal talks and sometimes group discussions with the FSWs on HIV prevention and condom use and this could positively contribute to enhancing the risk perception of the FSWs and improve their condom use behaviour with their clients.

"I show them, how to use condom, how to wear the condom using the penile model, I tell them not to allow the man to fix the condom because he can use his fingers to burst it. If they wear it wrongly, it should be thrown away and a new one used." (Chairlady)

"I talk to the FSWs sometimes. I sit with them and discuss many things about sexually transmitted infections. I even discuss with the male clients, some tell me they do not enjoy sex with condom but I tell them the benefits of condom use" (Female brothel owner)

Participants who were HIV prevention experts explained the evolution of HIV intervention efforts in the country towards empowering FSWs and putting them at the forefront in the planning and design of programs. The Minimum Prevention Package of Interventions (MPPI), which is the domesticated version of the global combination prevention approach, involves the combination of biomedical, structural and behavioural interventions. The prevention experts explain that the adoption of this approach in the country has also led to the involvement of FSWs and their communities in the design and implementation of HIV prevention interventions.

"The involvement of the target population is key and also bringing in the community where they exist to support their behaviour change also strengthens the approach." (Male HIV prevention expert)

"The adoption of the minimum prevention package of interventions approach has enabled a lot of sex workers who would have been keeping away from implementing partners to come out and be closer so they can assess services, and information on prevention, care and support. They can be part of the facilitating team to promote behavior change communication as part of policy and being the voice for other sex workers." (Male HIV prevention expert)

There was clear recognition by the experts that in the light of limited resources and the epidemic appraisals conducted in Nigeria, there is need to maximize the impact of HIV interventions by focusing interventions on key populations identified to be at high risk. They mentioned the identification of FSWs as a key population affected by the HIV epidemic in Nigeria and explained the evolution of the country's guidelines for the tailored implementation of HIV prevention programs for this target group.

\subsection{Barriers to Brothel leadership Inclusion}

\subsubsection{Inappropriate Attitude}

For the inclusion of brothel leadership in HIV prevention programs to be successful, specific attitudes are required of the brothel leaders to effectively foster a conducive atmosphere and environment for consistent condom use and other HIV prevention behaviours by the FSWs. Some brothel leaders mentioned being jovial, approachable, considerate, firm and kind, as some necessary attitudes required of a brothel leader without which their ability to foster such an environment will be hindered.

"You should apply wisdom, talk to them amicably and not with anger. Talk to them politely like a friend, approach the individual in a good manner so that the person will give you his or her attention." (Female brothel owner)

"We should be jovial with the customers and the girls. If you are jovial with your girls, they will not hide anything from you. I am very jovial with my girls and joke with them a lot. This makes them come close to me." (Female brothel owner)

Participants report that these attitudes are not just required to facilitate a conducive atmosphere within the brothel but also to support young FSWs and new entrants into sex work to integrate and effectively adopt consistent condom use behaviours within the establishment. 


\subsubsection{Lack of HIV-Related Knowledge}

In this study, the brothel leaders interviewed showed some knowledge of HIV and its prevention methods. The brothel leaders who participated in the pilot study showed knowledge of the high prevalence within the country and could describe correctly some methods of HIV prevention. Consistent condom use was mentioned by all as the most effective method of prevention, especially within the sex work environment. The brothel leaders who participated in the pilot intervention showed better knowledge of HIV compared to those who did not. They mentioned that prior to the intervention, they had various misconceptions about HIV and participating in the HIV intervention helped to dispel this. A brothel owner gives account of her misconceptions on HIV prevention and transmission:

"Before we believe that this sickness, STI disease or HIV, we can get it through toilet or through sharing something with someone. But since the intervention started and taught us how to take care of ourselves, we have now realized that HIV and STI diseases come through sex without condom. If you don't use condom consistently, HIV can be transmitted." (Chairlady)

HIV prevention experts within the study also acknowledge that sensitizing the brothel leaders on HIV, its prevention and management is important if their roles in fostering HIV prevention efforts within the brothels will be achieved.

"This can be included as part of the structural component of combination prevention interventions. If you get the brothel managers, owners, and chairladies involved in decision making, they are more likely to make the environment conducive for service providers to provide necessary services and make commodities available for sex workers either free or commercially." (Male HIV prevention expert)

\subsubsection{Non-Acceptance of HIV Prevention Responsibility}

For most interventions to be successful, the start up phase, which includes acceptance of all components of the intervention and consent by the participants, is important. Brothel leaders recognize the various benefits the brothel can gain from the implementation of HIV prevention interventions and their active participation in promoting condom use by the FSWs. Benefits mentioned include increased profits, better reputation as a 'clean brothel' and healthier FSWs (which could also increase profits due to less sick days off work). The brothel owners explain that sometimes clients try to assess the brothel to ascertain condom use by the girls.

"Some client come to check if we use condoms or not. For example, they can come and say they want sex without condom and if the girl says yes, they will say they want to urinate and then disappear without coming back again." (Chairlady)

In addition to the above, experts also mention that efforts need to be made to educate brothel leaders on the benefits of the interventions to the profitability and reputation of the brothel by program managers.

"For the implementation of the interventions and the institution of condom use rules in the brothels, you need the approval of the brothel owners. You need to educate them on the benefits of the intervention on the profitability of the business" (Male HIV prevention expert)

\subsection{Barriers to Condom Use}

Condom use barriers can impede efforts made by FSW towards correct and consistent condom use with all partners. There was a clear recognition of these barriers by the brothel leaders. Many brothel leaders mentioned excessive alcohol intake and substance abuse as major barriers to inconsistent condom use by FSWs.

'Some girls take drugs like 'igbo' (a local illicit non-injectable drug), some take drugs to have courage, and you know some girls say 'aah! If I don't take anything, I will be very shy to hustle, 'so they take all these things so they can have courage to hussle." (Chairlady)

Clients' offering FSWs more money for sex without condom was another recognized barrier to consistent condom use. The high level of poverty experienced by most FSWs, may negatively influence their susceptibility to enticements for non-condom use with clients. The influence of more money on consistent condom use by FSW varies and can be dependent on the FSWs' beliefs and assertiveness. A female brothel owner who did not participate in the pilot intervention explains how some FSWs in her brothel discuss non-use of condoms with their clients:

"There are some girls, who sometimes will sit down and thinking I cannot hear, discuss how a man comes and gives her N10 000, for sex without condom, She collects it and agrees and says she can take an analgesic to flush it out afterwards" (Female brothel owner) 
Conversely, some of the brothel owners gave instances within their brothels where the FSWs were insistent on condom use despite the client offering more money for non-condom use. Another consistent reason given by the participants for the non-use of condoms by the FSWs is the presence of boyfriends who put pressure on them not to use condoms for sexual acts with them. A participant gave an instance from her brothel:

"I have this girl that has a boyfriend around and whenever this girl is not around, the boyfriend will come to the brothel and pick another FSW. This was a constant problem with them." (Chairlady)

Some participants also mentioned non-availability of condoms as a barrier to condom use by the FSWs.

The brothel leaders recognized the need to always have condoms available in the brothels either for free or sold at subsidized rates within the brothel highlighting the important role they as brothel leaders can play in ensuring the constant availability of condoms within the brothel.

"I need the organizations to support me with condoms so I can provide them to the girls and help them. They usually are reluctant to spend their money on condoms."(Female brothel owner)

HIV prevention experts also discussed the unique roles brothel leaders can play in ensuring the constant availability of condoms in the brothels to facilitate condom use by the FSWs and her partners.

"I think that brothel mangers have a role to play in making sure that the brothel never runs out of condoms by ensuring that they have condoms for sale or for free available always thus deterring inconsistent condom use in the brothel." (Male HIV prevention expert)

The perceived risk to HIV infection by the FSWs has fundamental influence on participants' HIV related behaviour decisions and the adoption of HIV prevention interventions targeted at them. Many brothel leaders in this study mention how the prospect of being paid higher for sex without condom now has little or no appeal for the girls and the different ways the FSWs engage with and deal with various attempts by their clients to pay them higher for sex without condom. A brothel leader describes her view:

"So everybody is careful, even if they bring one million and say they should do without condom, the girls' will shout and push the person outside saying.... 'See this 'mugu' (abusive word) he wants me not to use condom'." (Chairlady)

"About this condom before, money can make the FSWs not to use condom but now, they have known that HIV doesn't show on the face, and it is not only HIV that is the disease that can kill, we have other STI diseases. So the program people taught them all these things and I don't think that somebody will expose herself to all those dangers again without using condom." (Male, brothel owner)

Many brothel leaders reported, also that these practices sometimes do not extend to the boyfriends and regular partners of the FSWs. They mention the sentimental attachment some girls have with their regular partners and boy friends which leads to not using condoms consistently with them.

"These boyfriends, they will come like one week, two weeks and then they will say to the girls; Ahhh we have known for long now, I like you, let us go straight without condom from now" (Chairlady)

"This boyfriend issue; some of the girls' have boyfriends and have sex without condom with them. I tell them that it is better to use a condom whenever you want to meet your boyfriend because you do not know where he has gone and if he is exposed or even HIV positive."(Chairlady)

\subsection{Program and Policy Considerations}

The criminalization of sex work in the country continues to impede the strides taken towards controlling the epidemic within this population. Experts mention the vagueness of the current legislation on soliciting for sex and sex work criminalization as bottlenecks, which continually compromise prevention efforts and program implementation.

The experts also explain that currently the HIV prevention interventions mainly consult with gatekeepers in sex work settings during advocacy at the entry stage of the interventions. They mention that it is important to include within existing guidelines and strategies the extent of gatekeepers' inclusion in interventions, as this will aid its institutionalization by relevant stakeholders.

"A clear definition of the extent to which gatekeepers should be involved in program implementation is needed and this will serve as guidance for the various actors implementing HIV programs in this environment. It will also guide the funding mechanisms to allocate funds and insist on its inclusion for all interventions." (Female HIV prevention expert) 
"If our guidelines include this and capacity is built on this, it will embed the brothel leadership inclusion within the standard HIV interventions for FSWs in the country and let all stakeholders see it as an important component that improves their programming. This will make sure it is part of the system and improve its sustainability. " (Female prevention expert)

\section{Discussion}

This study focuses on the perspectives of brothel leaders and HIV prevention experts on gatekeeper inclusion to current HIV prevention interventions for FSWs. Our findings show that the inclusion of gatekeepers within the immediate environment of the FSW can exert a positive influence on the institution of establishment policies on consistent condom use by the FSWs, promoting awareness to HIV/AIDs, conflict resolution and reinforcing protective behaviors among the FSWs. Similar studies support our findings that brothel leaders are strategically placed and possess the requisite authority to facilitate and support the promotion of a conducive social and physical environment in the brothel thus empowering the FSWs to negotiate condom use and other safe sex behaviours (Li et al., 2010; D. Morisky et al., 2006; Visrutaratna \& Lindan, 1995).

The orientation and support provided to new entrants into sex work and young FSWs on HIV prevention, consistent condom use and self-efficacy in the negotiation and use of condoms is another perceived contribution brothel leaders can provide in current efforts to curb the epidemic (D. E. Morisky, Tiglao, \& Sneed, 1998). Improving gatekeepers' supportive role towards consistent condom use may help to empower FSWs in their negotiation of condom use with clients and regular partners without fear of being punished or losing jobs (Yang et al., 2005).

The attitude of the brothel leader is important if he/she would be able to positively influence the FSWs and create a conducive environment for the implementation of HIV prevention interventions (Visrutaratna \& Lindan, 1995). Lack of HIV knowledge and the non-acceptance of their HIV prevention responsibility are other barriers which may impede the activities of brothel leaders in HIV prevention efforts (Yang et al., 2005). This is consistent with findings from other studies showing that FSW and gatekeeper knowledge of HIV/AIDs are important for the enhancement of HIV prevention efforts (FMOH, 2014; Huang, Henderson, Pan, \& Cohen, 2004; Li et al., 2010; Yang et al., 2005). Gatekeepers who lack knowledge regarding safe sex, might exhibit negative or neutral attitudes toward condom use and other protective behaviours (Visrutaratna \& Lindan, 1995). Hence, these brothel leaders may view their responsibilities in brothels primarily as maintaining and operating their business and thus show limited enthusiasm towards HIV prevention interventions (Egger et al., 2000; Yang et al., 2005). According to the Joint United Nations Program on HIV and AIDs (UNAIDS), the success of the $100 \%$ condom use programs among establishment-based FSWs in some countries in Asia suggests that HIV prevention efforts for FSWs should be a jointly owned responsibility by establishment gatekeepers, local health authorities, program managers as well as the FSWs themselves (Rojanapithayakorn, 2006; UNAIDS, 2000)

A perceived barrier to consistent condom use from the current study is the non-availability of condoms in the brothels. Brothel leaders can facilitate the uninterrupted availability of condoms in the establishment by stocking condoms for commercial sale at a subsidized rate or free to FSWs and clients. Studies show that clients and FSWs are more likely to use condoms when free or affordable condoms are available at the workplace (Egger et al., 2000; D. E. Morisky et al., 2002).

Our findings show that FSWs' consistent and correct condom use with all partners is an important component of their risk reduction. Brothel leaders can enhance FSWs' HIV/AIDs awareness in their establishment and thereby increase their awareness of HIV-related risks, which may positively influence condom use with their clients, boyfriends and regular partners. Inconsistent condom use with regular partners and boyfriends by FSWs remains problematic and still requires significant attention from both gatekeepers and HIV prevention experts. This conclusion is in line with recommendations in similar studies (Adeneye, Adeneye, Mafe, \& Adeiga, 2013; Asowa-Omorodion, 2000; D. Morisky et al., 2006; Murray et al., 2007; Okafor, Crutzen, Adebajo, et al., 2017).

While Nigeria's MPPI strategy for HIV prevention for FSWs is a domesticated version in line with the global UNAIDS combination prevention approach (UNAIDS, 2010), the limited consideration it places on the inclusion of gatekeepers within the immediate environment of the FSWS on HIV prevention efforts in Nigeria is evident (NACA, 2014). Similarly, no peer reviewed studies on interventions for gatekeeper support in HIV prevention programming exists in Nigeria. However, numerous studies exist in countries in Asia and the Dominican Republic and have shown that this is an important component which should be considered if gainful strides will be made towards curbing the epidemic (D. Morisky, Pena, \& Tiglao, 2002; Yang et al., 2005). Additional studies to support the inclusion of gatekeepers in HIV prevention interventions for sex workers are needed to explore country specific social and policy considerations for its implementation within the Nigerian context. Program managers, 
sex workers and their gatekeepers need to work together to design this approach and explore all possible scenarios where this inclusion is viable.

Despite the fact that this study allows us to address previously unexplored questions with this target group in Nigeria, a limitation of this study might be the social desirability bias. Brothel leaders may have provided socially desirable responses, which may overestimate their views in terms of being positive about the role of gatekeepers. Secondly, the study location limits the generalizability of the findings since the study was conducted in the administrative capital of Nigeria, which may accommodate more affluent sex work establishments, compared to other locations and in rural areas of the country.

\section{Conclusion}

The present study provides additional evidence on the potentially positive role of gatekeepers in HIV/AIDs related interventions for FSWs in Nigeria. It is expected that their inclusion into current programming will enhance the achievement of HIV/AIDs related milestones.

\section{Authors' Contributions}

UO collected the data, designed the study and drafted the manuscript revising it for intellectual content. $\mathrm{RC}$ and BDB contributed to the design of the study. EA contributed to the analysis and interpretation of the data. All authors critically reviewed the manuscript and approved the final version.

\section{Acknowledgements}

The authors thank the fellowship program of the Dutch Ministry of Foreign Affairs, The Netherlands, for funding this research. We want to thank also Faruna Idoko, Ngozi Ifeakocha, the representatives from brothels, Heartland Alliance, National Agency for the Control of Aids and the Society for Family Health for facilitating the conduct of this research.

\section{Competing Interests Statement}

The authors declared no potential conflict of interest.

\section{References}

Adeneye, A.K. , Adeneye, A.A., Mafe, M.A., \& Adeiga, A.A. (2013). Pattern of condom use and perceived risk of HIV infection among female sex workers in selected Brothels in Ogun State, Nigeria. International Journal of Public Health and Epidemiology, 2(5), 90-100.

Asowa-Omorodion, F. (2000). Sexual and health behaviour of commercial sex workers in Benin city, Edo state, Nigeria. Health Care for Women International, 21(4), 335-345. https://doi.org/10.1080/073993300245186

Egger, M., Pauw, J. , Lopatatzidis, A., Medrano, D. , Paccaud, F. , \& Smith, G.D. (2000). Promotion of condom use in a high-risk setting in Nicaragua: A randomized controlled trial. Lancet, 355, 2101-2105. https://doi.org/10.1016/S0140-6736(00)02376-X

FMOH. (2014). Nigeria integrated biological and behavioural surveillance survey 2014 (pp. 19-21). Abuja Nigeria Federal Ministry of Health

Hong, Y., Fang, X., Li, X., Liu, Y., \& Li, M. (2008). Environmental support and HIV prevention behaviors among female sex workers in China. Sexually Transmitted Diseases, 35(7), 662-667. https://doi.org/10.1097/OLQ.0b013e31816b322c

Huang, Y., Henderson, G.E., Pan, S., \& Cohen, M.S. (2004). HIV/AIDS risk among brothel-based female sex workers in China: Assessing the terms, content, and knowledge of sex work. Sexually Transmitted Diseases, 31(11), 695-700. https://doi.org/10.1097/01.olq.0000143107.06988.ea

Jana, S., Basu, I., Rotheram-Borus, M., \& Newman, P. (2004). The Sonagachi project: A sustainable community intervention program. AIDS Education and Prevention, 16(5), 405-414. https://doi.org/10.1521/aeap.16.5.405.48734

Li, Q., Li, X., Stanton, B., Fang, X., \& Zhao, R. (2010). A multilevel analysis of gatekeeper characteristics and consistent condom use among establishment-based female sex workers in Guangxi, China. Sexually Transmitted Diseases, 37(11), 700-705. https://doi.org/10.1097/OLQ.0b013e3181e1a2b2

Morisky, D., Pena, M., \& Tiglao, T. V. (2002). The impact of the work environment on condom use among female bar workers in the Philippines. Health Education and Behaviour, 29, 461-472. https://doi.org/10.1177/109019810202900406 
Morisky, D., Stein, J.A. , Chiao, C., Ksobiech, K., \& Malow, R. (2006). Impact of a social influence intervention on condom use and sexually transmitted infections among establishment-based female sex workers in the Philippines: A multilevel analysis. Health Psychology, 25(5), 595-603. https://doi.org/10.1037/0278-6133.25.5.595

Morisky, D. E., Stein, J. A., Sneed, C. D., Tiglao, T. V., Liu, K., Detels, R., \& Temponko, S. B. (2002). Modeling personal and situational influences on condom use among establishment-based commercial sex workers in the Philippines. AIDS and Behavior, 6, 163-172. https://doi.org/10.1023/A:1015401315918

Morisky, D. E., Tiglao, T. V., \& Sneed, C. D. (1998). The effects of establishment practices, knowledge and attitudes on condom use among Filipino sex workers. AIDS Care, 10, 213-220. https://doi.org/10.1080/09540129850124460

Murray, L. , Moreno, L. , Rosario, S. , Ellen, J., Sweat, M., \& Kerrigan, D. (2007). The role of relationship intimacy in consistent condom use among female sex workers and their regular paying partners in the Dominican Republic. AIDS and Behavior, 11, 463-470. doi: https://doi.org/10.1007/s10461-006-9184-5

NACA. (2014). National guidelines for implementation of HIV prevention programs for female sex workers in Nigeria (pp. 14-50). Abuja, Nigeria: National Agency for the Control of Aids (NACA).

Okafor, U. O., Crutzen, R., Adebajo, S., Okekearu, I., \& Van den Borne, H. (2017). Using brothel leadership to promote condom use among brothel-based female sex sorkers in Abuja, Nigeria: Study protocol for a cluster randomized pilot trial. BMC Pilot and feasibility studies, 3, 10. https://doi.org/10.1186/s40814-017-0124-0

Okafor, U. O., Crutzen, R., Okekearu, I., Adebajo, S., \& Van den Borne, H. (2017). HIV prevalence and high-risk behaviour of young brothel and non-brothel based female sex workers in Nigeria. BMC Res Notes, 10, 380 . doi: DOI 10.1186/s13104-017-2712-8

Page, C. G. (2002). The determination of organization stakeholder salience in public health. Journal of Public Health Management and Practice, 8(5), 76-84. doi: https://doi.org/10.1097/00124784-200209000-00009

Rogers, E. M. (2003). Diffusion of innovations, 5th Edition, Simon and Schuster (5th ed.): Simon and Schuster.

Rogers, E. M., \& Kincaid, D. L. (1981). Communication networks: Toward a new paradigm for research. Newyork: Free Press.

Rojanapithayakorn, W. (2006). The 100\% condom use programme in Asia. Reproductive Health Matters, 14(28), 41-52. https://doi.org/10.1016/S0968-8080(06)28270-3

UNAIDS. (2000). Evaluation of the $100 \%$ condom programme in Thailand. Retrieved from http://data.unaids.org/publications/irc-pub01/jc275-100pcondom_en.pdf website:

UNAIDS. (2010). Combination HIV prevention:Tailoring and coordinating biomedical, behavioural and structural strategies to reduce new HIV infections Retrieved from http://www.unaids.org/sites/default/files/media_assets/jc2007_combination_prevention_paper_en_pdf Assessed 29th Janaury 2016 website:

Urada, L. A., Morisky, D. E., Hernandez, L. I., \& Strathdee, S. A. (2013). Social and structural factors associated with consistent condom use among female entertainment workers trading sex in the Philippines. AIDS and Behaviour, 17(2), 523-535. https://doi.org/10.1007/s10461-011-0113-x

Visrutaratna, S., \& Lindan, C. P. (1995). 'Superstar' and 'model brothel': developing and evaluating a condom promotion program for sex establishments in Chiang Mai, Thailand. AIDS, 9(1), 69-75.

Xia, G., \& Yang, X. (2005). Risky sexual behavior among female entertainment workers in China: Implications for HIV/STD prevention intervention. AIDS Education and Prevention, 17(2), 143-156. https://doi.org/10.1521/aeap.17.3.143.62904

Yang, H. , Li, X., Stanton, B. , Fang, X., Zhao, R., Dong, B., . . Hong, Y. (2005). Condom use among female sex workers in China: Role of gatekeepers. Sexually Transmitted Diseases, 32(9), 572-580. https://doi.org/10.1097/01.olq.0000175418.48665.95

Zang, C., Li, X., \& Y., Hong. (2014). Relationship between female sex workers and gatekeeper: The impact on female sex worker's mental health in China. Psychology, Health and Medicine, 19(6). https://doi.org/10.1080/13548506.2013.869612 


\section{Copyrights}

Copyright for this article is retained by the author(s), with first publication rights granted to the journal.

This is an open-access article distributed under the terms and conditions of the Creative Commons Attribution license (http://creativecommons.org/licenses/by/4.0/). 